\title{
Nutritional immunology: function of natural killer cells and their modulation by resveratrol for cancer prevention and treatment
}

\author{
Christian Leischner ${ }^{1}$, Markus Burkard ${ }^{1,2}$, Matthias M. Pfeiffer ${ }^{3}$, Ulrich M. Lauer ${ }^{1}$, Christian Busch ${ }^{2,4}$ \\ and Sascha Venturelli $i^{*}$
}

\begin{abstract}
Natural killer (NK) cells as part of the innate immune system represent the first line of defence against (virus-) infected and malignantly transformed cells. The emerging field of nutritional immunology focuses on compounds featuring immune-modulating activities in particular on NK cells, which e.g. can be exploited for cancer prevention and treatment. The plant-based nutrition resveratrol is a ternary hydroxylated stilbene, which is present in many foods and beverages, respectively. In humans it comprises a large variety of distinct biological activities. Interestingly, resveratrol strongly modulates the immune response including the activity of NK cells. This review will give an overview on NK cell functions and summarize the resveratrol-mediated modulation thereof.
\end{abstract}

Keywords: Nutritional immunology, Resveratrol, Immune modulation, NK cell activity, Innate immune system

\section{Background}

The innate immune system is conserved among vertebrates and is already functionally present at birth. Cellular members of the human innate immune system are different leukocytes such as monocytes, eosinophils, neutrophils, basophils, dendritic cells, and natural killer (NK) cells. Other non-cellular members of the innate immune system are the complement system and a large number of secreted cytokines as inflammatory response to any given trigger. Thus the innate immune system forms a complex and effective protective shield against infections but also malignant transformation, and cancer, respectively. Interestingly, several natural compounds like resveratrol strongly influence the immune response and e.g. modulate the activity of NK cells. Therefore, the modulation of the innate immune system by nutritionderived compounds has an important and valuable impact on health. Due to the strong link between nutrition and cancer the field of nutritional immunology intensively

\footnotetext{
* Correspondence: sascha.venturelli@med.uni-tuebingen.de

${ }^{1}$ Department of Internal Medicine I, Medical University Hospital,

Otfried-Mueller-Str. 27, Tuebingen, Germany

Full list of author information is available at the end of the article
}

investigates immune-modulating substances that are present or even enriched in foods for cancer prevention and treatment.

\section{NK cells and immune response}

NK cells were first identified in 1975 by their ability to lyse cancer cells in vitro without prior immune sensitization $[1,2]$ and comprise about $15 \%$ of all circulating lymphocytes [3]. Their main importance lies in early host defence against both allogenic and autologous cells after virus infection [4], infection with bacteria or parasites, or against malignantly transformed cells [5]. NK cell development primarily occurs in the bone marrow (BM) environment: they are derived from hematopoietic stem cells subsequently differentiating into common lymphoid progenitors, which finally develop into NK/T progenitors, from which NK cells are derived throughout life [6-8]. Their lineage development is characterized by the sequential acquisition of surface receptors and effector functions [9]. In addition to BM and blood, NK cells are also found in peripheral tissues including liver, peritoneal cavity, and placenta [10]. Human NK cells are broadly defined as $\mathrm{CD}^{-} \mathrm{CD}^{-} 6^{+}$(CD3: T-cell co-receptor; CD56: neural cell 
adhesion molecule (NCAM)) lymphocytes and are further distinguished into CD56 bright ( $10 \%$ of human NK cells) and $\mathrm{CD}_{56} 6_{\mathrm{dim}}(\sim 90 \%$ of human NK cells) NK cells. $\mathrm{CD} 6_{\text {dim }}$ NK cells express high levels of Fcy receptor III (FcyRIII, CD16) mediating antibody-dependent cellmediated cytotoxicity (ADCC), and CD56 bright NK cells show less or no CD16 expression $[11,12]$. To defeat their targets NK cells are, after prior activation by cytokines, capable of extravasation and infiltration into affected tissues [13, 14]. Target cell killing is executed through different mechanisms (Fig. 1). First, NK cells form socalled immune synapses (dynamic interface formed between a NK cell and a target cell). Second, NK cells release cytoplasmic granules, organelles containing proteins like perforin (Prf1), the saposin-like family member granulysin, and serin-proteases called granzymes like granzyme B (GzmB) to cleave e.g. several pro-caspases, which then are able to trigger apoptosis in the target cell $[15,16]$. Furthermore, the expression of members of the tumour necrosis factor (TNF)-family like FAS ligand (FASL), TNF, and TNF-related apoptosis inducing ligand (TRAIL) are able to induce tumour-cell apoptosis upon formation of immune synapses. TRAIL can bind to several death receptors (DR), two of which are agonistic (DR4 (TRAIL-R1) and DR5 (TRAIL-R2)) and induce apoptosis, and two of which are antagonistic (decoy receptor 1 (DcR1, TRAILR3) and DcR2 (TRAIL-R4)) and cannot induce apoptosis. Another possibility to take action against target cells is the secretion of a number of effector cytokines such as interferon- $\gamma$ (IFN- $\gamma)$, granulocyte-macrophage colonystimulating factor (GM-CSF), and interleukin (IL) like IL-5, IL-10, or IL-13 after reaching distinct stages of NK-cell differentiation (Fig. 1). In addition, NK cells secrete a variety of chemokines including chemokine C-C motif ligand 2 (CCL2, monocyte-chemoattractant protein (MCP)-1), CCL3 (macrophage inflammatory protein

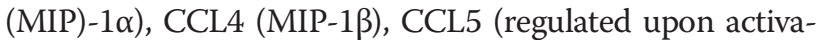
tion, normal T-cell expressed and secreted (RANTES)), chemokine X-C motif ligand 1 (XCL1, lymphotactin), and chemokine C-X-C motif ligand 8 (CXCL8, IL-8) to colocalize with other immune cells like dendritic cells in areas of inflammation (Fig. 1) [17]. With a wide range of pattern recognition receptors (PRRs), different types of immune cells can specifically identify conserved pathogenassociated molecular patterns (PAMPs), which are exclusively present on microbes such as viruses, bacteria, parasites, and fungi. Members of the main PRR families are transmembrane Toll-like receptors (TLRs), C-type lectin receptors (CLRs), cytoplasmic nucleotide oligomerization domain (NOD)-like receptors (NLRs), and RNA helicase retinoic acid inducible gene I (RIG-I)-like receptors (RLRs). Thus, an intracellular signalling can be activated that subsequently induces expression of genes involved in inflammatory and/or immune response to recruit e.g. phagocytic cells and effector molecules to the site of infection. NK cells express different PRRs like TLRs, NLRs, and RLRs. They directly respond to PAMPs in an appropriate environment in the presence of cytokines like IL-2, IL-12, IL-15, or IL-18. Thus, activated NK cells produce IFN- $\gamma$, GM-CSF, or TNF- $\alpha$, or release cytotoxic granules directed toward a target cell. Whether a NK cell remains silent or executes its killing capacity on malignant cells depends on the dynamic balance of stimulation events of two main structural classes of NK cell surface receptors, the killer cell immunoglobulin-like receptors (KIRs) and receptors of the C-type lectin-like family, which inhibit and/or activate signalling cascades (Fig. 1). Some of the human activating receptors like different KIRs or natural cytotoxicity receptors (NCRs) such as NKp30, NKp44, NKp46, and NKp80 transmit the activation signal via protein tyrosine kinasedependent pathways. Therefore, different transmembrane adaptor proteins comprise one to three cytoplasmic immunoreceptor tyrosine-based activation motifs (ITAMs) consisting of a consensus amino-acid sequence with tyrosines and leucines [18]. After phosphorylation the ITAMs serve as docking sites for other kinases to further pass the signalling. Additional activating signals can also be mediated through receptors, which are noncovalently associated with other adaptor proteins, which contain no ITAM [19]. To antagonize NK cell activation, inhibitory surface receptors like different KIRs in humans are present, which act through protein tyrosine phosphatase-dependent pathways [20]. They harbour immunoreceptor tyrosine-based inhibitory motifs (ITIMs) in their cytoplasmic domains, which can recruit tyrosine phosphatases like Src-homology 2 domain (SH2)-containing SHP-1 or SHP-2. The equilibrium of the phosphorylation status of several signalling molecules which are targets for both members of the Syk-family of protein tyrosine kinases zeta-chain-associated protein kinase 70/SYC (ZAP70/SYC), SHP-1, SHP-2 protein phosphatases, and its shifting to the one side or the other is therefore crucial for NK cell behaviour. Ligands for the inhibitory receptors are polymorphic major histocompatibility complex (MHC) class I molecules. KIR receptors bind groups of HLA-A, HLA-B, and HLA-C alleles, while HLA-E is recognized by CD94-NKG2A.

\section{Cancer and NK cell activities}

Some cancer cells lack or downregulate one or several MHC class I molecules and/or upregulate e.g. NKG2D ligands (NKG2DL) like the stress-inducible surface glycoproteins MHC class I-related chain A and B (MICA and MICB), and therefore provide no or not enough inhibitory stimulation [13, 21-23]. This so-called 'missingself' recognition enables NK cells to detect and destroy transformed or allogenic cells while discriminating them from normal host cells (Fig. 1) [24]. Unfortunately, cancer patients frequently have functionally impaired 


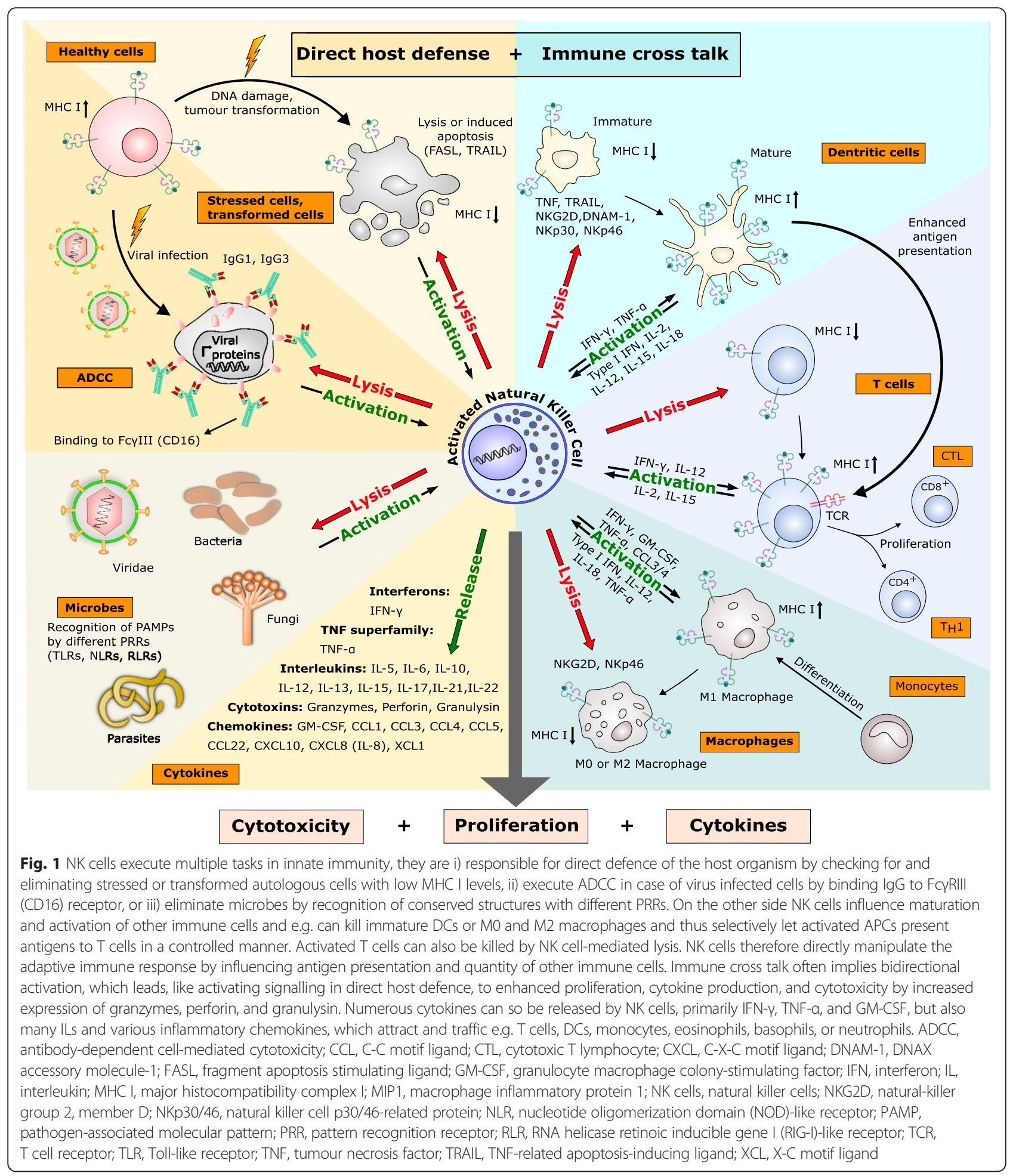

NK cells and therefore a hindered antitumour immune response [25-27]. Therefore, the application of pharmacological compounds that enhance NK cell function and/or restore immune surveillance is part of current antitumour strategies and treatment regimes. Immunomodulatory drugs like thalidomide and lenalidomide augment cytotoxicity in multiple myeloma and increase the amount of peripheral blood NK cells [28, 29]. Chemotherapeutics like melphalan, etoposide, and doxorubicin, or the proteasome inhibitor bortezomib trigger the upregulation of activating ligands for the receptors NKG2D and DNAX accessory molecule-1 (DNAM-1) on multiple 
myeloma cells, thus sensitizing them to NK cell-mediated killing [30]. In line, bortezomib at low concentrations inhibits proliferation in hepatocellular carcinoma with simultaneously increased MICA/B expression [31]. Especially, a large number of cytokines such as IL-2, IL-10, IL-12, IL-15, IL-18, IL-21, IL-23, and type I interferons $(\mathrm{IFN}-\alpha$, IFN- $\beta$ ) are investigated for their modulation potential towards NK cell activity [32]. IL-2 and IL-15 are commonly needed to expand donor NK cells in vitro in adoptive transfer therapy to stimulate proliferation in the periphery [33]. This activation leads to high membranebound TRAIL expression when compared to unstimulated cells [34]. IL-2 is FDA approved for the treatment of metastatic renal cancer and advanced malignant melanoma [35]. Whereas long-term low-dose subcutaneous application of IL-2 seems to be associated with a tolerable side-effect profile, the systemic use of IL-2 in high doses can result in severe side effects like vascular leak syndrome (VLS) and other toxicities [36-38]. Of note, several natural compounds strongly influence the immune response and especially modulate the activity of NK cells while concurrently displaying favourable toxicity profiles. Resveratrol, daily administered to healthy volunteers in oral doses up to $5 \mathrm{~g}$ for a period of 29 days, was shown to be safe without serious adverse reactions, which was proved by clinical, biochemical, or hematologic analyses [39].

\section{Resveratrol a plant-based diet}

The naturally occurring lipophilic plant polyphenol resveratrol was first isolated in 1939 from the roots of the white hellebore Veratrum grandiflorum O. Loes by Takaoka [40]. Since then, resveratrol was extracted from over 100 different plants, some of which serve as common human dietary sources like grapes (wine, grape juice), peanuts, soy, hop, and berries like blueberries and cranberries. Resveratrol belongs to the polyhydroxystilbene subclass of plant polyphenols and exists as two isomers, cis-(Z) and trans-(E) (Fig. 2a and b). The styrene double-bond can undergo isomerization during UV irradiation from the trans- to the cis-form [41]. In the naturally occurring glycoside piceid a glucose moiety is linked to cis- or trans-resveratrol via a 3-O- $\beta$-D-glycosidic bond, so that also two piceid isomers exist (Fig. 2c). In plants resveratrol serves as a phytoalexin (plant antibiotic) produced in response to fungal infection, injury, or UV irradiation [42-45], especially in grapevines, pines, and legumes. Resveratrol gained public attention associated with the "French paradox", a phrase describing the fact that the mortality rate from coronary heart disease (CHD) in France is lower than in the rest of Europe and the USA despite a diet traditionally rich in saturated fats and similar plasma cholesterol concentrations. Nevertheless, French mortality rates from $\mathrm{CHD}$ resemble more the ratios of Japan or China [46-48]. Corresponding data was a

1,2-Diphenylethylene (Stilbene)<smiles>C(=C\c1ccccc1)\c1ccccc1</smiles><smiles>C(=C/c1ccccc1)\c1ccccc1</smiles>

trans-Stilbene

b

3,5,4'-Trihydroxystilbene (Resveratrol)<smiles>Oc1cc(O)cc(/C=C/c2ccc(O)cc2O)c1</smiles>

C

Resveratrol-3-O- $\quad \beta$-D-glucopyranoside (Piceid)<smiles>OCCC(O)C(O)C(O)COc1cc(O)cc(/C=C\c2ccc(O)cc2)c1</smiles><smiles>OCCC(O)C(O)COc1cc(O)cc(/C=C/c2ccc(O)cc2)c1</smiles>

trans-Piceid

Fig. 2 The parent compound of resveratrol is a trihydroxylated stilbene (a). Resveratrol exists in two isomeric forms, cis and trans (b). Its natural occurring glycosidic form is piceid (c) with a glucose molecule linked via a 3-O- $\beta$-D-glycosidic bond to cis- or trans-resveratrol

acquired during the MONICA (Multinational MONItoring of trends and determinants in CArdiovascular disease) project organised by the World Health Organisation (WHO) in the 1980s to monitor cardiovascular diseases and to determine corresponding risk factors in 21 countries around the world. As possible explanation for this finding the consumption of red wine in France with its comparably high resveratrol content on a regular basis was suggested [49]. In fact, France had the highest per 
capita annual wine consumption worldwide during the period of data acquisition. Moreover, for resveratrol antioxidant [50,51], anti-inflammatory [52], neuroprotective [53], antiproliferative [54, 55], and distinctive immunomodulatory properties were shown [56]. Further, multiple examples for antitumoural effects of resveratrol are described in literature and comprehensively summarized by Han and colleagues for different tumour types [57]. Recent publications describe e.g. a synergistic effect of resveratrol in combination with doxorubicin in vitro and in vivo in the treatment of different breast cancer cell lines (MCF-7 and MDA-MB-231) [58] or dose-dependent induction of apoptosis in colon cancer cell lines like SW620 and HepG2 cells [59, 60].

\section{Bioavailability, pharmacokinetics, and biological functions of resveratrol}

Resveratrol is absorbed by intestinal trans-epithelial diffusion [61, 62]. In a clinical study by Walle et al. [63] at least $70 \%$ of ${ }^{14} \mathrm{C}$ - labelled resveratrol was taken up after oral administration. Further pharmacokinetic analyses revealed the highest resveratrol/metabolite levels $30 \mathrm{~min}$ after ingestion [64] with free resveratrol being present only to a small extent (1.7-1.9 \%). Resveratrol-3-O-sulfate, resveratrol-4'-Oglucuronide, and resveratrol-3-O-glucuronide are the major plasma metabolites, accounting for 2.4-up to 13-fold greater $\mathrm{C}_{\max }$ values in plasma than free resveratrol [65]. Almost $50 \%$ of resveratrol and its metabolites are bound to plasma proteins like albumin and haemoglobin [66] as well as low density lipoproteins (LDL) $[67,68]$. About $40-98 \%$ of orally administered resveratrol is excreted into urine and faeces within $24 \mathrm{~h} \mathrm{[69].} \mathrm{Resveratrol} \mathrm{first} \mathrm{gained} \mathrm{greater} \mathrm{at-}$ tention through its antioxidative activity against human LDL described in 1993 by Frankel et al. [51], thereby strengthening the "French paradox" hypothesis [46] via decreasing endothelial damage, which is pathophysiologically associated with cardiovascular disease. However, the antioxidant potential of resveratrol is less potent than that of quercetin or epicatechin, respectively flavonoids, which are more abundant in red wine than resveratrol [51]. Inhibition of platelet aggregation and eicosanoid synthesis by resveratrol due to decreased levels of thromboxane A2 (TxA2) via inhibition of cyclooxygenase-1 (COX1) was reported [70, 71]. This inhibiting property of resveratrol on cyclooxygenase activity plays a role in the production of pro-inflammatory molecules. In this context resveratrol acts as an anti-inflammatory molecule and was shown to reduce acute and chemically induced oedema [72, 73], lipopolysaccharide (LPS)-induced airway inflammation [74], and osteoarthritis [75]. Furthermore, resveratrol suppresses nuclear factor $\kappa$-light-chain-enhancer of activated B cells (NFKB)activation [76-78], thus influencing gene transcription regulating immune and inflammatory responses [79]. Since 1997 it is known that resveratrol also bears an anticancer activity being active throughout the steps of tumour initiation, promotion, and progression in vitro as well as in vivo. Therefore, resveratrol was considered as a cancer chemopreventive agent [72]. Resveratrol also activates sirtuin 1 [80], which is responsible e.g. for the regulation of glucose and insulin production, fat metabolism and, notably, prolonged cell survival through negative regulation of the tumour suppressor p53 [81]. Moreover, resveratrol was also described to prevent dysregulation of gap junctional intercellular communication (GJIC) mediated by organic peroxids and environmental toxicants [82, 83]. For cancer but also other diseases alterations in the GJIC have been reported and seem to play a crucial role during malignant transformation and tumour promotion. Therefore, the protection of an impairment of the cellular GJIC adds another interesting aspect to the anticancer function of resveratrol $[82,83]$.

\section{Resveratrol and its interplay with NK cells}

Several studies demonstrated a direct influence of resveratrol on NK cells and their killing ability on different levels (Fig. 3). Resveratrol exerts simultaneous effects on NK cells and other immune cells like $\mathrm{CD} 8^{+}$- and $\mathrm{CD} 4^{+}$-T-cells [84]. Falchetti and colleagues exposed peripheral blood mononuclear cells (PBMCs) to different concentrations of resveratrol for a period of $18 \mathrm{~h}$. After removing resveratrol, NK cell killing capacity of the PBMCs was tested against human immortalised myelogenous leukaemia K562 cells. The authors showed an increase of NK cell killing activity at low resveratrol concentrations ranging from $0.33 \mu \mathrm{M}$ to $5.48 \mu \mathrm{M}$, with maximum activity at $1.31 \mu \mathrm{M}$. However, a dose-related inhibition of lytic activity was observed at high resveratrol concentrations of $21.92 \mu \mathrm{M}$ and $87.68 \mu \mathrm{M}$. This finding was confirmed by $\mathrm{Li}$ and coworkers, who similarly demonstrated an inhibition of viability and increased apoptosis of NK cells upon incubation with high resveratrol concentrations $(50 \mu \mathrm{M})$, whereas low concentrations from $1.56 \mu \mathrm{M}$ to $3.13 \mu \mathrm{M}$ resulted in upregulation of NKG2D and IFN- $\gamma$ on mRNA as well as protein levels and an increased NK cell killing towards leukaemia K562 target cells (Fig. 3) [85]. These results suggest a concentration-dependent biphasic effect of resveratrol, which is explained by promoting cell apoptosis via caspase signalling pathway in high concentration ranges. This is supported by significantly reduced late apoptotic/necrotic cells after pretreatment with the caspase inhibitor $\mathrm{z}$-VAD-FMK. The latter study further showed a higher cytotoxic susceptibility of human lymphoblastoid T cells (Jurkat cells) towards resveratrol when compared to NK cells. This was further corroborated by $\mathrm{Lu}$ and Chen, who reported a similar dose-dependent increase of cytotoxic NK cell killing activity also against tumour cell lines derived from solid tumours, e.g. HepG2 and A549 cells after pre-stimulation of immortalized NK 


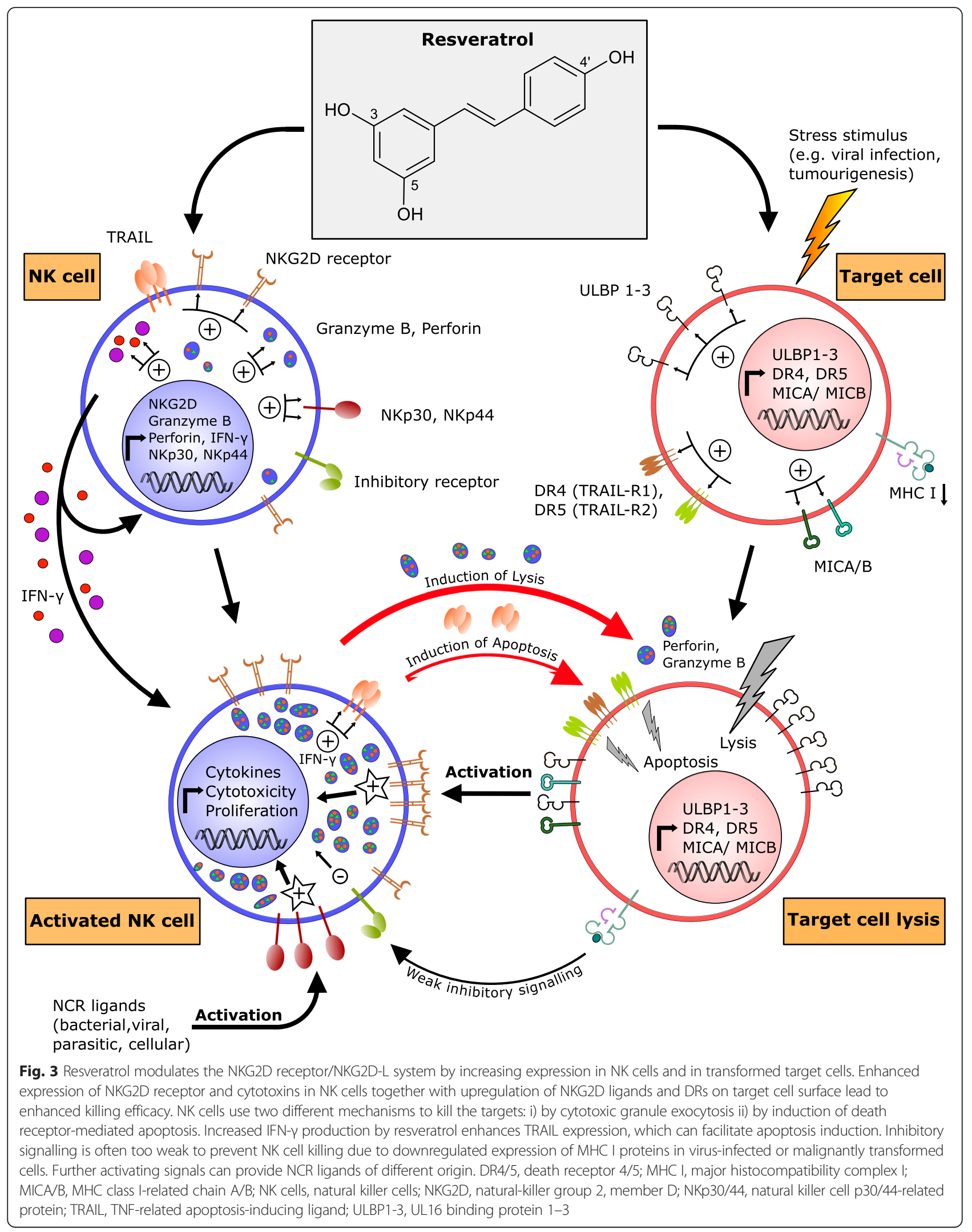


cells (NK-92 cells) with resveratrol at low concentrations of $1.56,6.25$, and $12.5 \mu \mathrm{M}$. All effector to target ratios (1:1, $5: 1,10: 1)$ showed similar effects with the highest enhancement of killing activity after pretreatment with $12.5 \mu \mathrm{M}$ resveratrol for the 10:1 ratio [86]. The authors additionally demonstrated a dose-dependent upregulation of perforin expression and a dose-dependent phosphorylation of ERK-1/2 and JNK in resveratrol-stimulated NK-92 cells. ERK-1/2 and JNK have previously been shown to contribute to NKG2D-mediated cytotoxicity [87]. Using a murine acute pneumonia model to evaluate the anti-infectious properties of resveratrol, subsequently displayed an enhanced NK cell activity with an increased anticancer effect [88]. In the latter study resveratrol was intragastrically administered to rats for 3 days at $0.5 \mathrm{mg} / \mathrm{kg}$ body weight. The rats were subsequently intratracheally inoculated with Serratia marcescens, a common nosocomial pathogen, and monitored for $24 \mathrm{~h}$. The resveratrol-treated group showed an increased alveolar macrophage (AM) infiltration, an elevated NK cell activity, and a decreased bacterial burden in the lungs of the infected animals, with a decreased mortality. Interestingly, isolated spleen NK cells of rats pretreated with resveratrol showed an enhanced killing efficacy against mouse ${ }^{51} \mathrm{Cr}$-labelled lymphoma YAC-1 target cells compared with spleen NK cells isolated from control rats treated with saline. In addition to the abovementioned modes of action, resveratrol increases cellsurface expression of NKG2D ligands on human promyeloblastic leukaemia KG-1a cells, thus providing two complementary mechanisms to strengthen cytokine-induced killer cells (CIK, a mixed phenotype between T- and NK cells) killing properties directly and indirectly [89]. Stimulation of KG-1a cells with $25 \mu \mathrm{M}$ resveratrol for $24 \mathrm{~h}$ rendered KG-1a cells susceptible to CIK-mediated cytolysis via an increase in cell-surface expression of NKG2D ligands and receptor DR4, coupled with a downregulation of cell-surface expression of DcR1 in KG-1a cells, and accompanied by activation of the TRAIL pathway [89]. Resveratrol is further capable of sensitizing cells of various cancer entities to TRAIL-induced apoptotic cell death such as neuroblastoma, medulloblastoma, glioblastoma, melanoma, T-cell leukaemia, pancreatic-, breast-, and colon cancer (Fig. 3) [90-92]. In this respect, resveratrol upregulates the agonistic receptors DR4 and DR5 in androgen-insensitive human prostate carcinoma cells PC3 and DU-145 [93, 94], thus enhancing TRAIL sensitivity and possibly facilitating NK cell-mediated killing. Likewise, enhancement of DR4 and DR5 surface expression on TRAIL-resistant human prostate adenocarcinoma LNCaP cells with no difference for DcR1/2 after treatment with $10 \mu \mathrm{M}$ resveratrol for $48 \mathrm{~h}$ was reported. Further, a dosedependent activation of caspase-3 for resveratrol treatment alone, and caspase- 8 activation for combined treatment with resveratrol and TRAIL was shown. For PC-3 prostate cancer cells similar results were obtained concerning increase of receptor expression of DR4 and DR5 for resveratrol treatment with $10 \mu \mathrm{M}$ and $20 \mu \mathrm{M}$ for $48 \mathrm{~h}$, and caspase $3 / 8$ activation for treatment with resveratrol (0-30 $\mu \mathrm{M})$ and in combination with TRAIL (25 $\mathrm{nM})$. Human 1205 LU metastatic melanoma cells show a resveratrol-dependent enhanced sensitivity to TRAIL through downregulation of the antiapoptotic proteins cFLIP and Bcl-xL [95]. Resveratrol also significantly enhances CD95L expression on HL60 human leukaemia cells and on T47D breast carcinoma cells after $24 \mathrm{~h}$ of treatment [96], which in addition facilitates NK cells to trigger signalling-dependent apoptosis. Nieswandt et al. showed a connection of platelet aggregation and the susceptibility of cancer cells to NK cell-mediated lysis [97]. In this respect, mouse and human cancer cells can activate platelets and their aggregation, which correlates with their metastatic potential $[98,99]$. Due to tumour cell-platelet aggregation, circulating tumour cells (CTCs) can be coated by aggregated platelets and thus escape the immune response, which further facilitates metastasis. Interestingly, resveratrol mediates a dose-dependent inhibition of platelet aggregation via reduction of integrin gpIIb/IIIa on the platelet membrane, which acts as fibrinogen receptor involved in clot formation through the formation of bridges between platelets, and by reducing the production of TxA2, which activates further platelets and thus increases aggregation, through inhibition of COX1-dependent pathways [71]. In the field of NK cells resveratrol could further possess therapeutic potential in defeating aggressive NK cell leukaemias and lymphomas by inhibiting constitutively active signal transducers and activators of transcription 3 (STAT3) signalling, which was demonstrated in the work of Quoc Trung and colleagues in 2013 [100].

\section{Conclusion}

Modulation of NK cell activity by nutrition-derived compounds and the role of resveratrol

Historically, the impact of nutrition on immune function first came to light in 1810 when thymic atrophy in malnourished patients was described by J.F. Menkel [101]. Especially in the last decade, the field of nutritional immunology or immunonutrition has constantly been growing and established many molecular connections between dietary compounds and their influence on immune cells. Some of the different NK cell modulating compounds can occur in numerous plants with often very variable content like quercetin [102]. Since up to $70 \%$ of the body's immunocytes and over $90 \%$ of all Igproducing cells are located in the gut, which is therefore considered as the largest immune organ, the influence of nutrient compounds on human immunity by making first contact with the receptors of the immune cells in this area, is obvious [103, 104]. Moreover, the gut- 
associated lymphoid tissue (GALT), consisting of isolated and aggregated lymphoid follicles, is exposed to myriads of different food antigens and multiple microorganisms ingested with the daily diet. It is therefore predestinated for immunomodulation by nutrients e.g. through targeting PAMP receptors of innate immune cells. Immune-modulating molecules can be endogenous or exogenous, and share the ability to enhance or suppress immune responses. Many plant-derived secondary metabolites like flavonoids exhibit stimulating properties on NK cell activity. The flavonol quercetin enhances NK cell killing activity towards YAC-1 target cells [105]. Another study described an increased susceptibility of leukaemia K562, and gastric cancer SNU1 and SNU-C4 cells towards NK cell-mediated lysis through induced expression of different NKG2D ligands [106]. Myricetin from red wine and other foods showed similar stimulating effects towards K562 cells [107]. In the latter study, however, quercetin did not alter NK cell killing activity. Moreover, amentoflavone treated mice showed enhanced NK cell activity and ADCC. Furthermore, IL-2 and IFN$\gamma$ production was increased [108]. There are also examples of natural compounds, which are non-supportive for the immune system e.g. tangeritin, a flavone found in tangerine and other citrus peels, significantly reducing the number of lymphocytes in mice treated with $100 \mu \mathrm{M}$ tangeritin in the drinking water for 4 weeks [109]. In another study, inhibitory effects of tangeritin on NK cell proliferation and differentiation with an $\mathrm{ED}_{50}$ (i.e., dose that is effective in half the cultures) between $1 \mu \mathrm{M}$ and $10 \mu \mathrm{M}$, were observed [110]. In line with the immunemodulating properties of nutrition-derived compounds resveratrol has been described to affect NK cell function directly and indirectly on different levels. Resveratrol seems to enhance immune reactions e.g. via alteration of the expression of activating cell surface receptors like NKG2D on NK cells or via stimulation of the expression of their corresponding ligands on malignant cells as summarized in Fig. 3. This immune modulation is very interesting in the context of the further molecular properties of this natural compound. For resveratrol, a histone deacetylase (HDAC) inhibitory function in different human hepatoblastoma cells towards the classical HDACs (class I, II and IV) was detected. It was postulated, that HDAC inhibition mediated a dose-dependent reduction of cancer cell proliferation [111]. Interestingly, one preclinical approach for the activation of the NK cell population and a subsequent increased cancer cell killing is upregulation of the expression of the excitatory NKG2D ligands by HDAC inhibitors [23, 112]. In detail, Armeanu and colleagues demonstrated an enhancement of cell-surface expression of MICA/B in HepG2 and Hep3B hepatoma cells with no alterations of ULBP1-3 levels upon stimulation with the HDAC inhibitor valproic acid (VPA), which led to an enhanced NK cellmediated killing [23]. Contrariwise, pretreatment of NK cells alone with classical HDAC inhibitors like VPA or suberoylanilide hydroxamic acid (SAHA) at therapeutic concentrations suppresses the cytolytic activity of NK cells [113]. Resveratrol is probably one of the most famous natural food ingredients due to its suspected ability to lower the incidence of coronary heart disease in people consuming wine with a high resveratrol content on a regular basis like in France, hence the name "French paradox". Nonetheless, despite the beneficial properties, including antitumour activities of resveratrol, an important aspect remains to be discussed. Most studies and experiments concerning the immune-stimulatory activity of resveratrol were performed in vitro and ex vivo, respectively with supraphysiological concentrations. The content of resveratrol in different fruits, vegetables, and especially in processed foods as well as the bioavailability has to be taken into account while evaluating the biological activity of resveratrol. A study about the absorption of wine-related polyphenols including resveratrol in different matrices like wine, grape juice, and vegetable juice revealed maximum serum peak concentrations around $30 \mathrm{~min}$ after consumption with maximal serum concentrations of only $10-40 \mathrm{nM}$ after consumption of $25 \mathrm{mg}$ trans-resveratrol per $75 \mathrm{~kg}$ body weight (dissolved in $100 \mathrm{ml}$ beverage, resulting in a concentration of $1.095 \mathrm{mM}$ ), which is considerably lower than the concentrations tested in vitro showing beneficial effects [64]. Accordingly, therapeutically required concentrations are not achievable without further dietary supplementation, which argues against an exclusive role of resveratrol in providing health-promoting properties by regular wine consumption alone. Resveratrol content of different French wines ranges from 0.6-6.8 mg/l (2.63$29.79 \mu \mathrm{M})$ [114], which is between 416- and 37-fold less than in the above mentioned absorption study. Taken together, resveratrol is a promising natural compound able to stimulate immune responses including an increase of the NK cell-mediated killing of (virus-) infected and malignantly transformed cells. Problems arise, however, in reaching pharmacologically effective systemic plasma concentrations, because of rapid phase II-metabolism and renal elimination. Nonetheless, suitable dietary intake of resveratrol could provide beneficial health effects.

\footnotetext{
Abbreviations

ADCC: antibody-dependent cell-mediated cytotoxicity; APC: antigen presenting cell; BM: bone marrow; CCL: C-C motif ligand; CDS: cytosolic DNA sensor; CHD: coronary heart disease; CIK: cytokine-induced killer cell; CLR:

C-type lectin receptor; COX1: cyclooxygenase-1; CTC: circulating tumour cell; CTL: cytotoxic T Iymphocyte; CXCL: C-X-C motif ligand; DNAM-1: DNAX accessory molecule-1; DR4/5: death receptor 4/5; FASL: fragment apoptosis stimulating ligand; GALT: gut-associated lymphoid tissue; GJC: gap junctional intercellular communication; GM-CSF: granulocyte macrophage colony-stimulating factor; GzmB: granzyme B; HDAC: histone deacetylase; IFN: interferon; IL: interleukin; ITAM: immunoreceptor tyrosine-based
} 
activation motif; ITIM: immunoreceptor tyrosine-based inhibitory motif; KIR: killer cell immunoglobulin-like receptor; LDL: low density lipoprotein; MHC I: major histocompatibility complex I; MICA/B: MHC class I-related chain A/B; MIP1: macrophage inflammatory protein 1; NCAM: neural cell adhesion molecule; NCR: natural cytotoxicity receptor; NK cell: natural killer cell; NKG2D: natural-killer group 2, member D; NKp30/44: natural killer cell p30/ 44-related protein; NKp30/46: natural killer cell p30/46-related protein; NLR: nucleotide oligomerization domain (NOD)-like receptor: PAMP: pathogen-associated molecular pattern; PBMC: peripheral blood mononuclear cell; Prfl: perforin; PRR: pattern recognition receptor; RANTES: regulated upon activation, normal T-cell expressed and secreted; RLR: RNA helicase retinoic inducible gene I (RIG-I)-like receptor; SAHA: suberoylanilide hydroxamic acid; STAT3: transducer and activator of transcription 3; TCR: T cell receptor; TLR: Toll-like receptor; TNF: tumour necrosis factor: TRAIL: TNF-related apoptosis-inducing ligand: TXA2: thromboxane A2; ULBP1-3: UL16 binding protein 1-3; VLS: vascular leak syndrome; VPA: valproic acid; WHO: World Health Organisation; XCL: X-C motif ligand.

\section{Competing interests}

The authors declare that they have no competing interests.

\section{Authors' contributions}

$\mathrm{CL}, \mathrm{CB}$, and $\mathrm{SV}$ planned and drafted the manuscript. $\mathrm{CL}$ performed the bibliographic search and designed the figures. $C L, M B$, and $S V$ structured the review. Further proofreading was performed and additional helpful comments were given by MMP, UML, and CB. All authors read and approved the final manuscript.

\section{Acknowledgements}

The authors wish to thank Dr. Alexander Berger for contributions to the aquisition of data and stimulating discussions. This work was supported by grants from the German Childhood Cancer Foundation ((DKS), project 2012.14 and 2014.19), the Wissenschaftsfoerderung der Deutschen Brauwirtschaft e.V. (Wifoe), project B103), and PASCOE pharmazeutische Praeparate GmbH. SV was further supported by the Institutional Strategy of the Eberhard Karls University of Tuebingen (Deutsche Forschungsgemeinschaft (DFG), ZUK 63). We further acknowledge support by the DFG and the Open Access Publishing Fund of the Eberhard Karls University of Tuebingen. The sponsors had no involvement neither in the study design, collection, analysis, and interpretation of data, nor in the writing of the manuscript and in the decision to submit the manuscript for publication.

\section{Author details}

'Department of Internal Medicine I, Medical University Hospital, Otfried-Mueller-Str. 27, Tuebingen, Germany. ${ }^{2}$ Division of Dermatologic Oncology, Department of Dermatology and Allergology, University of Tuebingen, Tuebingen, Germany. ${ }^{3}$ Department of Pediatric Hematology and Oncology, University Children's Hospital, Tuebingen, Germany. ${ }^{4}$ Pallas Clinic, Olten, Switzerland.

\section{Received: 29 October 2015 Accepted: 25 April 2016 Published online: 04 May 2016}

\section{References}

1. Kiessling R, Klein E, Wigzell H. "Natural" killer cells in the mouse. I. Cytotoxic cells with specificity for mouse moloney leukemia cells. Specificity and distribution according to genotype. Eur J Immunol. 1975;5(2):112-7. doi:10.1002/eji.1830050208.

2. Herberman RB, Nunn ME, Lavrin DH. Natural cytotoxic reactivity of mouse lymphoid cells against syngeneic and allogeneic tumors. I. Distribution of reactivity and specificity. Int J Cancer. 1975;16(2):216-29. doi:10.1002/ijc. 2910160204.

3. Robertson MJ, Ritz J. Biology and clinical relevance of human natural killer cells. Blood. 1990;76(12):2421-38.

4. Lee S-H, Miyagi T, Biron CA. Keeping NK cells in highly regulated antiviral warfare. Trends Immunol. 2007;28(6):252-9. http://dx.doi.org/10.1016/j.it. 2007.04.001
5. Biron CA, Brossay L. NK cells and NKT cells in innate defense against viral infections. Curr Opin Immunol. 2001;13(4):458-64. http://dx.doi.org/10.1016/ S0952-7915(00)00241-7.

6. Freud AG, Caligiuri MA. Human natural killer cell development. Immunol Rev. 2006;214(1):56-72. doi:10.1111/j.1600-065×.2006.00451.x.

7. Colucci F, Caligiuri MA, Di Santo JP. What does it take to make a natural killer? Nat Rev Immunol. 2003;3(5):413-25.

8. Blom B, Spits H. Development of human lymphoid cells. Annu Rev Immunol. 2006;24(1):287-320. doi:10.1146/annurev.immunol.24.021605.090612.

9. Luevano M, Madrigal A, Saudemont A. Generation of natural killer cells from hematopoietic stem cells in vitro for immunotherapy. Cell Mol Immunol. 2012;9(4):310-20.

10. Moffett-King A. Natural killer cells and pregnancy. Nat Rev Immunol. 2002; 2(9):656-63.

11. Cooper MA, Fehniger TA, Caligiuri MA. The biology of human natural killercell subsets. Trends Immunol. 2001;22(11):633-40. http://dx.doi.org/10.1016/ S1471-4906(01)02060-9.

12. Batoni G, Esin S, Favilli F, Pardini M, Bottai D, Maisetta G, et al. Human CD56bright and CD56dim natural killer cell subsets respond differentially to direct stimulation with mycobacterium bovis bacillus calmette-guérin. Scand J Immunol. 2005:62(6):498-506. doi:10.1111/j.1365-3083.2005.01692.x.

13. Biron CA. Activation and function of natural killer cell responses during viral infections. Curr Opin Immunol. 1997:9(1):24-34. http://dx.doi.org/10.1016/ S0952-7915(97)80155-0.

14. Fogler WE, Volker K, McCormick KL, Watanabe M, Ortaldo JR, Wiltrout RH. NK cell infiltration into lung, liver, and subcutaneous B16 melanoma is mediated by VCAM-1NLA-4 interaction. J Immunol. 1996;156(12):4707-14.

15. Trapani JA, Davis J, Sutton VR, Smyth MJ. Proapoptotic functions of cytotoxic lymphocyte granule constituents in vitro and in vivo. Curr Opin Immunol. 2000;12(3):323-9. http://dx.doi.org/10.1016/S0952-7915(00)00094-7.

16. Krzewski K, Strominger JL. The killer's kiss: the many functions of NK cell immunological synapses. Curr Opin Cell Biol. 2008;20(5):597-605. http://dx. doi.org/10.1016/j.ceb.2008.05.006

17. Walzer T, Dalod M, Robbins SH, Zitvogel L, Vivier E. Natural-killer cells and dendritic cells: 'I'union fait la force'. Blood. 2005;106(7):2252-8. doi:10.1182/ blood-2005-03-1154

18. Moretta A, Bottino C, Vitale M, Pende D, Cantoni C, Mingari MC, et al. Activating receptors and coreceptors involved in human natural killer cell-mediated cytolysis. Annu Rev Immunol. 2001;19(1):197-223. doi:10.1146/annurev.immunol. 19.1.197.

19. Malhotra A, Shanker A. NK cells: immune cross-talk and therapeutic implications. Immunotherapy. 2011;3(10):1143-66. doi:10.2217/imt.11.102.

20. Narni-Mancinelli E, Ugolini S, Vivier E. Tuning the threshold of natural killer cell responses. Curr Opin Immunol. 2013;25(1):53-8. http://dx.doi.org/10. 1016/j.coi.2012.11.005

21. Lanier LL. NK cell recognition. Annu Rev Immunol. 2005;23(1):225-74. doi:10. 1146/annurev.immunol.23.021704.115526

22. Raulet DH, Guerra N. Oncogenic stress sensed by the immune system: role of natural killer cell receptors. Nat Rev Immunol. 2009:9(8):568-80.

23. Armeanu S, Bitzer M, Lauer UM, Venturelli S, Pathil A, Krusch M, et al. Natural killer cell-mediated lysis of hepatoma cells via specific induction of NKG2D ligands by the histone deacetylase inhibitor sodium valproate. Cancer Res. 2005:65(14):6321-9. doi:10.1158/0008-5472.can-04-4252.

24. Karre K, Ljunggren $\mathrm{HG}$, Piontek $\mathrm{G}$, Kiessling R. Selective rejection of H-2deficient lymphoma variants suggests alternative immune defence strategy. Nature. 1986;319(6055):675-8

25. Fauriat C, Mallet F, Olive D, Costello RT. Impaired activating receptor expression pattern in natural killer cells from patients with multiple myeloma. Leukemia. 2006;20(4):732-3. http://www.nature.com/leu/journal/ v20/n4/suppinfo/2404096s1.html.

26. Konjević G, Mirjačić Martinović K, Vuletić A, Jović V, Jurisić V, Babović N, et al. Low expression of CD161 and NKG2D activating NK receptor is associated with impaired NK cell cytotoxicity in metastatic melanoma patients. Clin Exp Metastasis. 2007:24(1):1-11. doi:10.1007/s10585-006-9043-9.

27. Jinushi M, Takehara T, Tatsumi T, Hiramatsu N, Sakamori R, Yamaguchi S, et al. Impairment of natural killer cell and dendritic cell functions by the soluble form of MHC class I-related chain A in advanced human hepatocellular carcinomas. J Hepatol. 2005:43(6):1013-20. doi:http://dx.doi.org/10.1016/j.jhep.2005.05.026.

28. Tai Y-T, Li X-F, Catley L, Coffey R, Breitkreutz I, Bae J, et al. Immunomodulatory drug lenalidomide (CC-5013, IMiD3) augments anti-CD40 SGN-40-induced 
cytotoxicity in human multiple myeloma: clinical implications. Cancer Res. 2005;65(24):11712-20. doi:10.1158/0008-5472.can-05-1657.

29. Davies FE, Raje N, Hideshima T, Lentzsch S, Young G, Tai YT, et al. Thalidomide and immunomodulatory derivatives augment natural killer cell cytotoxicity in multiple myeloma. Blood. 2001;98(1):210-6.

30. Soriani A, Zingoni A, Cerboni C, lannitto ML, Ricciardi MR, Di Gialleonardo V et al. ATM-ATR-dependent up-regulation of DNAM-1 and NKG2D ligands on multiple myeloma cells by therapeutic agents results in enhanced NK-cell susceptibility and is associated with a senescent phenotype. Blood. 2009; 113(15):3503-11. doi:10.1182/blood-2008-08-173914.

31. Armeanu S, Krusch M, Baltz KM, Weiss TS, Smirnow I, Steinle A, et al. Direct and natural killer cell-mediated antitumor effects of Low-dose Bortezomib in hepatocellular carcinoma. Clin Cancer Res. 2008;14(11):3520-8. doi:10. 1158/1078-0432.ccr-07-4744.

32. Smyth MJ, Cretney E, Kershaw MH, Hayakawa Y. Cytokines in cancer immunity and immunotherapy. Immunol Rev. 2004;202(1):275-93. doi:10. 1111/j.0105-2896.2004.00199.x.

33. Sutlu T, Alici E. Natural killer cell-based immunotherapy in cancer: current insights and future prospects. J Intern Med. 2009;266(2):154-81. doi:10.1111/ j.1365-2796.2009.02121.x.

34. Mirandola P, Ponti C, Gobbi G, Sponzilli I, Vaccarezza M, Cocco L, et al. Activated human NK and CD8+ T cells express both TNF-related apoptosis-inducing ligand (TRAIL) and TRAIL receptors but are resistant to TRAlL-mediated cytotoxicity. Blood. 2004;104(8):2418-24. doi:10.1182/blood-2004-04-1294.

35. Rosenberg SA, Yang JC, Topalian SL, Schwartzentruber DJ, Weber JS, Parkinson DR, et al. Treatment of 283 consecutive patients with metastatic melanoma or renal cell cancer using high-dose bolus interleukin 2. Jama. 1994;271(12):907-13.

36. Rosenstein M, Ettinghausen SE, Rosenberg SA. Extravasation of intravascular fluid mediated by the systemic administration of recombinant interleukin 2. J Immunol. 1986;137(5):1735-42.

37. Maloy KJ, Powrie F. Fueling regulation: IL-2 keeps CD4+ treg cells fit. Nat Immunol. 2005;6(11):1071-2.

38. Schlegel $P$, Teltschik HM, Pfeiffer $M$, Handgretinger R, Schumm M, Koscielniak E, et al. Long-term IL-2 therapy after transplantation of T cell depleted stem cells from alternative donors in children. Best Pract Res Clin Haematol. 2011;24(3):443-52. doi:10.1016/j.beha.2011.04.007.

39. Brown VA, Patel KR, Viskaduraki M, Crowell JA, Perloff M, Booth TD, et al. Repeat dose study of the cancer chemopreventive agent resveratrol in healthy volunteers: safety, pharmacokinetics, and effect on the insulin-like growth factor axis. Cancer Res. 2010;70(22):9003-11. doi:10.1158/0008-5472.CAN-10-2364.

40. Takaoka M. The phenolic substances of white hellebore (veratrum grandiflorum loes fil.) II. Nippon Kagaku Kaishi. 1939;60(12):1261-4.

41. Kalantari H, Das DK. Physiological effects of resveratrol. BioFactors. 2010; 36(5):401-6. doi:10.1002/biof.100.

42. Langcake P, Pryce RJ. The production of resveratrol by vitis vinifera and other members of the vitaceae as a response to infection or injury. Physiol Plant Pathol. 1976;9(1):77-86. http://dx.doi.org/10.1016/0048-4059(76)90077-1.

43. Langcake P, Cornford CA, Pryce RJ. Identification of pterostilbene as a phytoalexin from vitis vinifera leaves. Phytochemistry. 1979;18(6):1025-7. http://dx.doi.org/10.1016/S0031-9422(00)91470-5.

44. Hart JH. Role of phytostilbenes in decay and disease resistance. Annu Rev Phytopathol. 1981;19(1):437-58. doi:10.1146/annurev.py.19.090181.002253.

45. Jeandet $P$, Bessis $R$, Gautheron $B$. The production of resveratrol (3,5,4'trihydroxystilbene) by grape berries in different developmental stages. Am J Enol Vitic. 1991;42(1):41-6.

46. Renaud S, de Lorgeril M. Wine, alcohol, platelets, and the french paradox for coronary heart disease. Lancet. 1992;339(8808):1523-6. http://dx.doi.org/10. 1016/0140-6736(92)91277-F.

47. B-I L, Zhang X, Zhang W, H-n Z. New enlightenment of french paradox: Resveratrol's potential for cancer chemoprevention and anti-cancer therapy. Cancer Biol Ther. 2007:6(12):1833-6. doi:10.4161/cbt.6.12.5161.

48. Cooper KA, Chopra M, Thurnham DI. Wine polyphenols and promotion of cardiac health. Nutr Res Rev. 2004;17(1):111-30. doi:10.1079/NRR200482.

49. Kopp P. Resveratrol, a phytoestrogen found in red wine. A possible explanation for the conundrum of the 'french paradox'? Eur J Endocrinol. 1998;138(6):619-20. doi:10.1530/eje.0.1380619.

50. Kawada N, Seki S, Inoue M, Kuroki T. Effect of antioxidants, resveratrol, quercetin, and $\mathrm{N}$-acetylcysteine, on the functions of cultured rat hepatic stellate cells and kupffer cells. Hepatology. 1998;27(5):1265-74. doi:10.1002/ hep.510270512.
51. Frankel EN, Waterhouse AL, Kinsella JE. Inhibition of human LDL oxidation by resveratrol. Lancet. 1993;341(8852):1103-4.

52. Wadsworth TL, Koop DR. Effects of the wine polyphenolics quercetin and resveratrol on pro-inflammatory cytokine expression in RAW 264.7 macrophages. Biochem Pharmacol. 1999;57(8):941-9. http://dx.doi.org/10.1016/S0006-2952(99)00002-7.

53. Rege SD, Kumar S, Wilson DN, Tamura L, Geetha T, Mathews ST, et al. Resveratrol protects the brain of obese mice from oxidative damage. Oxidative Med Cell Longev. 2013;2013:7. doi:10.1155/2013/419092.

54. Schneider $Y$, Vincent F, Duranton Bt, Badolo L, Gossé F, Bergmann C et al. Anti-proliferative effect of resveratrol, a natural component of grapes and wine, on human colonic cancer cells. Cancer Letters. 2000;158(1):85-91. doi:http://dx.doi.org/10.1016/S0304-3835(00)00511-5.

55. ElAttar TM, Virji AS. Modulating effect of resveratrol and quercetin on oral cancer cell growth and proliferation. Anticancer Drugs. 1999;10(2):187-93.

56. Gao X, Xu YX, Janakiraman N, Chapman RA, Gautam SC. Immunomodulatory activity of resveratrol: suppression of lymphocyte proliferation, development of cell-mediated cytotoxicity, and cytokine production1. Biochem Pharmacol. 2001;62(9):1299-308. http://dx.doi.org/10. 1016/S0006-2952(01)00775-4

57. Han G, Xia J, Gao J, Inagaki Y, Tang W, Kokudo N. Anti-tumor effects and cellular mechanisms of resveratrol. Drug Discoveries Ther. 2015;9(1):1-12. doi:10.5582/ddt.2015.01007.

58. Rai G, Mishra S, Suman S, Shukla Y. Resveratrol improves the anticancer effects of doxorubicin in vitro and in vivo models: a mechanistic insight Phytomedicine. 2016;23(3):233-42. doi:10.1016/j.phymed.2015.12.020.

59. Chen $H$, Jin ZL, Xu H. MEK/ERK signaling pathway in apoptosis of SW620 cell line and inhibition effect of resveratrol. Asian Pac J Trop Med. 2016:9(1): 49-53. doi:10.1016/j.apjtm.2015.12.010.

60. Liu MH, Lin XL, Li J, He J, Tan TP, Wu SJ, et al. Resveratrol induces apoptosis through modulation of the Akt/FoxO3a/Bim pathway in HepG2 cells. Mol Med Rep. 2016;13(2):1689-94. doi:10.3892/mmr.2015.4695.

61. Walle T. Bioavailability of resveratrol. Ann N Y Acad Sci. 2011;1215(1):9-15. doi:10.1111/j.1749-6632.2010.05842.x.

62. Kuhnle G, Spencer JPE, Chowrimootoo G, Schroeter H, Debnam ES, Srai SKS, et al. Resveratrol is absorbed in the small intestine as resveratrol glucuronide. Biochem Biophys Res Commun. 2000;272(1):212-7. http://dx.doi.org/10.1006/bbrc.2000.2750.

63. Walle T, Hsieh F, DeLegge MH, Oatis JE, Walle UK. High absorption but very low bioavailability of oral resveratrol in humans. Drug Metab Dispos. 2004;32(12):1377-82. doi:10.1124/dmd.104.000885.

64. Goldberg DM, Yan J, Soleas GJ. Absorption of three wine-related polyphenols in three different matrices by healthy subjects. Clin Biochem. 2003;36(1):79-87. http://dx.doi.org/10.1016/S0009-9120(02)00397-1.

65. Patel KR, Scott E, Brown VA, Gescher AJ, Steward WP, Brown K. Clinical trials of resveratrol. Ann N Y Acad Sci. 2011;1215(1):161-9. doi:10.1111/j.17496632.2010.05853.x

66. Burkon A, Somoza V. Quantification of free and protein-bound transresveratrol metabolites and identification of trans-resveratrol-C/Oconjugated diglucuronides - Two novel resveratrol metabolites in human plasma. Mol Nutr Food Res. 2008;52(5):549-57. doi:10.1002/mnfr.200700290.

67. Jannin B, Menzel M, Berlot J-P, Delmas D, Lançon A, Latruffe N. Transport of resveratrol, a cancer chemopreventive agent, to cellular targets: plasmatic protein binding and cell uptake. Biochem Pharmacol. 2004;68(6):1113-8. http://dx.doi.org/10.1016/j.bcp.2004.04.028.

68. Lu Z, Zhang Y, Liu H, Yuan J, Zheng Z, Zou G. Transport of a cancer chemopreventive polyphenol, resveratrol: interaction with serum albumin and hemoglobin. J Fluoresc. 2007;17(5):580-7. doi:10.1007/s10895-007-0220-2.

69. Boocock DJ, Faust GES, Patel KR, Schinas AM, Brown VA, Ducharme MP, et al. Phase I dose escalation pharmacokinetic study in healthy volunteers of resveratrol, a potential cancer chemopreventive agent. Cancer Epidemiol Biomark Prev. 2007;16(6):1246-52. doi:10.1158/1055-9965.epi-07-0022.

70. Pace-Asciak CR, Hahn S, Diamandis EP, Soleas G, Goldberg DM. The red wine phenolics trans-resveratrol and quercetin block human platelet aggregation and eicosanoid synthesis: implications for protection against coronary heart disease. Clin Chim Acta. 1995;235(2):207-19. http://dx.doi. org/10.1016/0009-8981(95)06045-1.

71. Toliopoulos IK, Simos YV, Oikonomidis S, Karkabounas SC. Resveratrol diminishes platelet aggregation and increases susceptibility of K562 tumor cells to natural killer cells. Indian J Biochem Biophys. 2013;50(1):14-8.

72. Jang M, Cai L, Udeani GO, Slowing KV, Thomas CF, Beecher CWW, et al. Cancer chemopreventive activity of resveratrol, a natural product derived 
from grapes. Science. 1997;275(5297):218-20. doi:10.1126/science.275.5297. 218.

73. Chen G, Shan W, Wu Y, Ren L, Dong J, Ji Z. Synthesis and anti-inflammatory activity of resveratrol analogs. Chem Pharm Bull. 2005;53(12):1587-90. doi:10.1248/cpb.53.1587.

74. Birrell MA, McCluskie K, Wong S, Donnelly LE, Barnes PJ, Belvisi MG. Resveratrol, an extract of red wine, inhibits lipopolysaccharide induced airway neutrophilia and inflammatory mediators through an NF-KBindependent mechanism. FASEB J. 2005. doi:10.1096/fj.04-2691fje.

75. Elmali N, Esenkaya I, Harma A, Ertem K, Turkoz Y, Mizrak B. Effect of resveratrol in experimental osteoarthritis in rabbits. Inflamm Res. 2005;54(4):158-62. doi:10.1007/s00011-004-1341-6.

76. Manna SK, Mukhopadhyay A, Aggarwal BB. Resveratrol suppresses TNFinduced activation of nuclear transcription factors NF-KB, activator protein-1, and apoptosis: potential role of reactive oxygen intermediates and lipid peroxidation. J Immunol. 2000;164(12):6509-19. doi:10.4049/jimmunol.164. 12.6509 .

77. Kundu JK, Shin YK, Kim SH, Surh Y-J. Resveratrol inhibits Phorbol esterinduced expression of COX-2 and activation of NF-KB in mouse skin by blocking IKB kinase activity. Carcinogenesis. 2006;27(7):1465-74. doi:10.1093/ carcin/bgi349

78. Faith SA, Sweet TJ, Bailey E, Booth T, Docherty JJ. Resveratrol suppresses nuclear factor-kappaB in herpes simplex virus infected cells. Antiviral Res. 2006;72(3):242-51.

79. Lenardo MJ, Baltimore D. NF-KB: a pleiotropic mediator of inducible and tissue-specific gene control. Cell. 1989;58(2):227-9. http://dx.doi.org/10.1016/ 0092-8674(89)90833-7.

80. Howitz KT, Bitterman K, Cohen HY, Lamming DW, Lavu S, Wood JG, et al, Small molecule activators of sirtuins extend saccharomyces cerevisiae lifespan. Nature. 2003;425(6954):191-6. http://www.nature.com/nature/ journal/v425/n6954/full/nature01960.html.

81. Vaziri H, Dessain SK, Eaton EN, Imai S-I, Frye RA, Pandita TK, et al. hSIR2SIRT1 functions as an NAD-dependent p53 deacetylase. Cell. 2001;107(2):149-59. http://dx.doi.org/10.1016/S0092-8674(01)00527-X.

82. Sovadinova I, Babica P, Boke H, Kumar E, Wilke A, Park JS, et al. Phosphatidylcholine specific PLC-induced dysregulation of Gap junctions, a robust cellular response to environmental toxicants, and prevention by resveratrol in a Rat liver cell model. PloS one. 2015;10(5):e0124454. doi:10. 1371/journal.pone.0124454.

83. Upham BL, Guzvic M, Scott J, Carbone JM, Blaha L, Coe C, et al. Inhibition of gap junctional intercellular communication and activation of mitogenactivated protein kinase by tumor-promoting organic peroxides and protection by resveratrol. Nutr Cancer. 2007;57(1):38-47. doi:10.1080/ 01635580701268188

84. Falchetti R, Fuggetta MP, Lanzilli G, Tricarico M, Ravagnan G. Effects of resveratrol on human immune cell function. Life Sci. 2001;70(1):81-96. http://dx.doi.org/10.1016/S0024-3205(01)01367-4.

85. Li Q, Huyan T, Ye L-J, Li J, Shi J-L, Huang Q-S. Concentration-dependent biphasic effects of resveratrol on human natural killer cells in vitro. J Agric Food Chem. 2014;62(45):10928-35. doi:10.1021/j502950u.

86. Lu C-C, Chen J-K. Resveratrol enhances perforin expression and NK cell cytotoxicity through NKG2D-dependent pathways. J Cell Physiol. 2010;223(2):343-51. doi:10.1002/jcp.22043.

87. Chen X, Trivedi PP, Ge B, Krzewski K, Strominger JL. Many NK cell receptors activate ERK2 and JNK1 to trigger microtubule organizing center and granule polarization and cytotoxicity. Proc Natl Acad Sci. 2007;104(15):6329-34. doi:10.1073/pnas.0611655104.

88. Lu C-C, Lai H-C, Hsieh S-C, Chen J-K. Resveratrol ameliorates Serratia marcescens-induced acute pneumonia in rats. J Leukoc Biol. 2008;83(4):1028-37. doi:10.1189/jlb.0907647.

89. Hu L, Cao D, Li Y, He Y, Guo K. Resveratrol sensitized leukemia stem cell-like KG-1a cells to cytokine-induced killer cells-mediated cytolysis through NKG2D ligands and TRAIL receptors. Cancer Biol Ther. 2012;13(7):516-26. doi:10.4161/cbt.19601.

90. Fulda S, Debatin K-M. Sensitization for tumor necrosis factor-related apoptosis-inducing ligand-induced apoptosis by the chemopreventive agent resveratrol. Cancer Res. 2004;64(1):337-46. doi:10.1158/0008-5472.can03-1656.

91. Fulda S, Debatin K-M. Resveratrol-mediated sensitisation to TRAlL-induced apoptosis depends on death receptor and mitochondrial signalling. Eur J Cancer. 2005;41(5):786-98. http://dx.doi.org/10.1016/j.ejca.2004.12.020.
92. Jacquemin G, Shirley S, Micheau O. Combining naturally occurring polyphenols with TNF-related apoptosis-inducing ligand: a promising approach to kill resistant cancer cells? Cell Mol Life Sci. 2010;67(18):3115-30. doi:10.1007/s00018-010-0407-6.

93. Shankar S, Chen Q, Siddiqui I, Sarva K, Srivastava RK. Sensitization of TRAILresistant LNCaP cells by resveratrol (3, 4, 5 tri-hydroxystillbene): molecular mechanisms and therapeutic potential. J Mol Signal. 2007;2:7. doi:10.1186/ 1750-2187-2-7.

94. Shankar S, Siddiqui I, Srivastava R. Molecular mechanisms of resveratrol (3,4,5trihydroxy-trans-stilbene) and its interaction with TNF-related apoptosis inducing ligand (TRAIL) in androgen-insensitive prostate cancer cells. Mol Cell Biochem. 2007;304(1-2):273-85. doi:10.1007/s11010-007-9510-x.

95. Ivanov VN, Partridge MA, Johnson GE, Huang SXL, Zhou H, Hei TK. Resveratrol sensitizes melanomas to TRAIL through modulation of antiapoptotic gene expression. Exp Cell Res. 2008;314(5):1163-76. http://dx.doi.org/10.1016/j.yexcr.2007.12.012

96. Clement MV, Hirpara JL, Chawdhury SH, Pervaiz S. Chemopreventive agent resveratrol, a natural product derived from grapes, triggers CD95 signalingdependent apoptosis in human tumor cells. Blood. 1998;92(3):996-1002.

97. Nieswandt B, Hafner M, Echtenacher B, Männel DN. Lysis of tumor cells by natural killer cells in mice is impeded by platelets. Cancer Res. 1999;59(6): 1295-300.

98. Heinmoller E, Weinel RJ, Heidtmann HH, Salge U, Seitz R, Schmitz I, et al. Studies on tumor-cell-induced platelet aggregation in human lung cancer cell lines. J Cancer Res Clin Oncol. 1996;122(12):735-44.

99. van Es N, Sturk A, Middeldorp S, Nieuwland R. Effects of cancer on platelets. Semin Oncol. 2014;41(3):311-8. http://dx.doi.org/10.1053/j.seminoncol.2014. 04.015.

100. Quoc Trung L, Espinoza JL, Takami A, Nakao S. Resveratrol induces cell cycle arrest and apoptosis in malignant NK cells via JAK2/STAT3 pathway inhibition. PloS one. 2013;8(1), e55183. doi:10.1371/journal.pone.0055183.

101. Jackson CM. The effects of inanition and malnutrition upon growth and structure. Philadelphia, PA: Blakiston's Sons and Co; 1925.

102. Pang C, Mak J, Ismail R, Ong C. In vitro modulatory effects of flavonoids on human cytochrome P450 2C8 (CYP2C8). Naunyn-Schmiedeberg's Arch Pharmacol. 2012;385(5):495-502. doi:10.1007/s00210-012-0731-5.

103. Brandtzaeg P, Johansen F-E. Mucosal B cells: phenotypic characteristics, transcriptional regulation, and homing properties. Immunol Rev. 2005; 206(1):32-63. doi:10.1111/j.0105-2896.2005.00283.x.

104. Jung C, Hugot JP, Barreau F. Peyer's P: The immune sensors of the intestine. Int J Inflamm. 2010;2010:823710. doi:10.4061/2010/823710.

105. Yu C-S, Lai K-C, Yang J-S, Chiang J-H, Lu C-C, Wu C-L, et al. Quercetin inhibited murine leukemia WEHI-3 cells in vivo and promoted immune response. Phytother Res. 2010;24(2):163-8. doi:10.1002/ptr.2841.

106. Bae JH, Kim JY, Kim MJ, Chang SH, Park YS, Son CH, et al. Quercetin enhances susceptibility to NK cell-mediated lysis of tumor cells through induction of NKG2D ligands and suppression of HSP70. J Immunother. 2010;33(4):391-401.

107. Lindqvist C, Bobrowska-Hagerstrand M, Mrowczynska L, Engblom C, Hagerstrand H. Potentiation of natural killer cell activity with myricetin. Anticancer Res. 2014;34(8):3975-9.

108. Guruvayoorappan C, Kuttan G. Amentoflavone, a biflavonoid from Biophytum sensitivum augments lymphocyte proliferation, natural killer cell and antibody dependent cellular cytotoxicity through enhanced production of IL-2 and IFN-gamma and restrains serum sialic acid and gamma glutamyl transpeptidase production in tumor - bearing animals. J Exp Ther Oncol. 2007:6(4):285-95.

109. Vanhoecke BW, Delporte F, van Braeckel E, Heyerick A, Depypere HT, Nuytinck $\mathrm{M}$, et al. A safety study of oral tangeretin and xanthohumol administration to laboratory mice. In Vivo. 2005;19(1):103-7.

110. Bracke ME, Depypere HT, Boterberg T, Van Marck VL, Vennekens KM, Vanluchene $E$, et al. Influence of tangeretin on Tamoxifen's therapeutic benefit in mammary cancer. J Natl Cancer Inst. 1999;91(4):354-9. doi:10. 1093/jnci/91.4.354.

111. Venturelli S, Berger A, Böcker A, Busch C, Weiland T, Noor S, et al. Resveratrol as a Pan-HDAC inhibitor alters the acetylation status of jistone proteins in human-derived hepatoblastoma cells. PloS one. 2013;8(8): e73097. doi:10.1371/journal.pone.0073097.

112. Diermayr S, Himmelreich H, Durovic B, Mathys-Schneeberger A, Siegler U, Langenkamp $U$, et al. NKG2D ligand expression in AML increases in response to HDAC inhibitor Valproic acid and contributes to allorecognition 
by NK-cell lines with single KIR-HLA class I specificities. Blood. 2008;111(3): 1428-36. doi:10.1182/blood-2007-07-101311.

113. Ogbomo H, Michaelis M, Kreuter J, Doerr HW, Cinatl Jr J. Histone deacetylase inhibitors suppress natural killer cell cytolytic activity. FEBS Lett. 2007;581 (7):1317-22. doi:10.1016/j.febslet.2007.02.045.

114. Ribeiro de Lima MT, Waffo-Téguo P, Teissedre PL, Pujolas A, Vercauteren J,

Cabanis JC, et al. Determination of stilbenes (trans-astringin, cis- and

trans-piceid, and cis- and trans-resveratrol) in Portuguese wines. J Agric

Food Chem. 1999;47(7):2666-70. doi:10.1021/jf9900884.

Submit your next manuscript to BioMed Central and we will help you at every step:

- We accept pre-submission inquiries

- Our selector tool helps you to find the most relevant journal

- We provide round the clock customer support

- Convenient online submission

- Thorough peer review

- Inclusion in PubMed and all major indexing services

- Maximum visibility for your research

Submit your manuscript at www.biomedcentral.com/submit 